J. Egypt. Soc. Parasitol. (JESP), 50(3), 2020: 683-688

(Online: 2090-2549)

\title{
BLASTOCYSTIS HOMINIS IN DIABETIC AND NON-DIABETIC PATIENTS WITH IRRITABLE BOWEL SYNDROME IN BENI-SUEF CITY, EGYPT
}

By

SHIMAA S. IBRAHIM ${ }^{1 *}$, MOUSA A. M. ISMAIL ${ }^{2}$, MARWA ABDALLAH SHAKER ${ }^{3}$, DOAA MAHMOUD KHALILI ${ }^{4}$, and AMIRA RAAFAT ${ }^{2}$

Department of Parasitology ${ }^{1}$, Faculty of Medicine, Beni-Suef University, Department of Medical Parasitology ${ }^{2}$, Faculty of Medicine, Cairo University, Department of Tropical Medicine ${ }^{3}$, and Department of Community ${ }^{4}$, Faculty of Medicine, Beni-Suef University, Egypt ("correspondence: drshimaa85@yahoo.com)

Abstract

Blastocystis is an opportunistic infection that is considered to cause gastro-intestinal symptoms, including inflammatory bowel syndrome (IBS). It was also found that diabetic patients might be at a higher risk of infection with intestinal parasites causing gastro-intestinal symptoms especially Blastocystis. This study assessed the rate of Blastocystis infection in patients suffering from IBS associated with diabetes mellitus (DM), in comparison with the non-diabetic IBS group. Two hundred stool samples were collected. All the participants were IBS-diagnosed patients. It is noted that 100 were without any history of chronic diseases based on history taking, while the other 100 were known to be diabetic. Blastocystis was diagnosed by direct microscopy of wet preparations; Lugol's iodine staining after concentration, and Modified Jones' Culture. Blastocystis was detected in $37 \%, 65 \%, \& 87 \%$ samples, respectively in IBS diabetic patients. But, the parasite was found in $21 \%, 25 \%, \& 42 \%$ samples, respectively in IBS non-diabetic patients. The only considerable risk factor for Blastocystis infection was the presence of DM, as it increased the possibility of infection more than 9 times.

Key words: Diabetic patients, Blastocystis hominis, Irritable bowel syndrome.

\section{Introduction}

Blastocystis hominis is a common anaerobic unicellular protozoan of the human intestine worldwide (Eroglu et al, 2009). In humans, the prevalence of blastocystosis was higher in developing countries $53.8 \%$ than in developed ones 3.3\% (Alfellani et al, 2013). It was considered as a commensal organism in fecal samples. Blastocystis pathogenic potential was questionable; due to controversy data as was reported in asymptomatic (Tanaka, 2008) and symptomatic persons (Khademvatan et al, 2017). Risk factors associated with blastocystosis included poor hygiene, close contact with infected animals, and consumption of contaminated food or water (Meloni et al, 2011). The clinical manifestations associated with blastocystosis were abdominal pain and distension, vomiting, acute or chronic diarrhea, constipation, alternating diarrhea and constipation, skin rash, and fatigue (Boorom et al, 2008).

Blastocystis was diagnosed by microscopic examination of fecal material, with or without Lugol's iodine stains and identified by vacuole, multi-vacuoles, granular, amoebaid, and cystic (Coyle et al, 2012). Concentration techniques as formal-ethyl acetate technique was suitable for preservation and diagnosis (Bogoch et al, 2006), PCR and culture were used (Suresh and Smith, 2004). The short-term cultivation of fecal samples for 48-72hrs was highly sensitive and cheap (Nascimento et al, 2005).

Blastocystis species was one of the direct or indirect causes of gastro-intestinal symptoms as with some cases of IBS (Scanlan, 2012). IBS is a functional gastrointestinal disorder, with prevalence rates of 35\%- $43 \%$ in developing countries and 5\%-24\% in developed countries (Lepczyńska et al, 2016). The postulated pathogenesis of this infection in IBS includes the low-grade inflammation caused by the constant immune activation induced by Blastocystis (Coyle et al, 2012). It was found that the IgG antibody levels to Blastocystis were significantly higher in the patients with IBS than in the asymptomatic controls (Hussain et al, 1997).

In developing countries, intestinal parasit- 
osis caused significant morbidity (Abdel Fadil et al, 2018) and mortality particularly in immunocompromised people (Stark et al, 2009) as well as those suffered from chronic diseases and metabolic disorders with weak immune system (Aulagnon et al, 2014).

Generally speaking, type 2 diabetes (DM) proved to be a major health worldwide problem. This metabolic disease was indicated by high blood glucose levels due to insufficient insulin production by pancreas and diabetic subjects were known to be more susceptible to infectious diseases (Berbudi et al, 2020). The chronic hyperglycemias cause impairment in innate and acquired immunity, ending with immunosuppressive condition (Knapp, 2013). In Egypt, both types 1 \& 2 of diabetes mellitus were encountered (ElTawdy et al, 2016) and globally, people with diabetes mellitus had quadrupled in the past three decades, and diabetes becomes the $9^{\text {th }}$ major cause of death (Zheng et al, 2018).

The present study aimed to assess the rate of Blastocystis hominis infection in patients suffering from IBS associated with DM, in comparison with non-diabetic IBS patients.

\section{Patients and Methods}

This is a case-control study performed on a total of 200stool samples collected from patients attended the outpatient clinics of Internal Medicine and Tropical Medicine Departments, Faculty of Medicine, Beni-Suef University Hospitals. The study was done in the period from November 2018 to May 2019. All participants were IBS patients, 100 were without any history of immunodeficiency, or chronic diseases based on medical history (control positive) and 100 randomly selected diabetic patients of both sexes on either hypoglycemic drugs or insulin treatment.

Inclusion criteria were patients of both sexes, and aged $\geq 20$ with a history of IBS symptoms with or without DM. Exclusion criteria were non-IBS patients on anti-parasitic drugs, or antibiotics, bismuth, mineral oil, or barium during the previous 2 weeks. Only individuals who offered at least three stool samples were included in the study. Sheets were filled out on all participants including personal and medical history data as well as clinical examinations.

Diagnosis of DM was based on the American Diabetes Association criteria as fasting plasma glucose $\geq 126 \mathrm{mg} / \mathrm{dl}$, or $2 \mathrm{hrs}$ plasma glucose $\geq 200 \mathrm{mg} / \mathrm{dl}$ during oral glucose tolerance test (OGTT), or hemoglobin A1C level $\geq 6.5 \%$ (Roden, 2016).

Parasitological diagnosis: Three stool samples were taken from each participant in labeled carton boxes. The stool samples were examined macroscopically for consistency and gravid segments...etc. The microscopic examined was done by direct Lugol's Iodine stained smear, and formal-ether concentration method and examined under low and high power magnifications. Also, a portion of each stool sample was cultured in Modified Jones' medium and incubated at $37^{\circ} \mathrm{C}$ for 48 72hr (Hassan et al, 2016).

Statistical analysis: Data were analyzed by using the statistical package of social science (SPSS) software version 25 for windows 10. Simple descriptive analysis was in the form of numbers and percentages of qualitative data and arithmetic means as a central tendency measurement, standard deviations as a measure of quantitative parametric data. For quantitative parametric data the independent samples t-test was used to compare between two groups. Chi square test was used to compare between more than two qualitative groups. Binary logistic regression analysis was done to predict the acquisition of blastocystosis infection from different baseline independent variables as diabetes, age, sex, occupation and/or residence. $\mathrm{P}$-value $<0.05$ was considered statistically significant.

\section{Results}

The study involved both sexes; were females having IBS and. The DM patients were $31 \%$ males and $69 \%$ females with a mean of $45.9 \pm 13.7$. The IBS non-diabetic patients or controls were $39 \%$ males and $61 \%$ females with a mean of $48.3 \pm 14.2$. There was no significant difference between detection of $B$. hominis in DM patients and controls as to 
ages $(\mathrm{P}=0.232)$ or sexes $(\mathrm{P}=0.236)$. Also, other variants as residence and occupation didn't show significant difference among participants (Tab. 1).

The clinical manifestations only the bowel habits changes and flatulence showed significant difference between DM patients and controls $(\mathrm{P}<0.001 \& \mathrm{P}=0.053$, respectively), but, the DM types of treatments did not show significant difference (Tab. 2).

The stool samples efficacy of direct wet mount smear, Lugol's Iodine stained after concentration, and modified Jones' culture as reference index for blastocystosis diagnosis were in (37) $37 \%$, (65) 65\%, \& (87) $87 \%$ respectively in IBS-diabetic patients, but were in (21) $21 \%$, , (25) $25 \%$, \& (42) $42 \%$ respectively, in IBS non-diabetic patients (Tab. 3).

Standard diagnostic indices including sensitivity, specificity, positive predictive value (PPV), negative predictive value (NPV) and diagnostic efficacy were calculated for each technique (Tab. 4).

Blastocystosis risk factor was only diabetes with increased the possibility of infection more than 9 times (OR, 95\% CI was 9.4, 4.6 to19.3).

The details given in tables $(1,2,3,4 \& 5)$.

Table 1: Positive B. hominis in diabetic patients, and controls as to socio-demographic and environmental characteristics.

\begin{tabular}{|l|l|l|l|}
\hline Variants & Cases of IBS with DM positive culture N=87 & Controls DM negative culture N=42 & P-value* \\
\hline Age & $47.1 \pm 13.9$ & $48.6 \pm 15.4$ & 0.563 \\
$\geq 20$ & $2(2.3 \%)$ & $0(0 \%)$ & \\
$21-30$ & $11(12.6 \%)$ & $7(16.7 \%)$ & 0.730 \\
$31-40$ & $20(23 \%)$ & $7(16.7 \%)$ & \\
$41-50$ & $14(16.1 \%)$ & $10(23.8 \%)$ & \\
$51-60$ & $31(35.6 \%)$ & $14(33.3 \%)$ & \\
$\geq 60$ & $9(10.3 \%)$ & $4(9.5 \%)$ & 0.227 \\
\hline Males & $24(27.6 \%)$ & $16(38.1 \%)$ & 0.262 \\
Females & $63(72.4 \%)$ & $26(61.9 \%)$ & \\
\hline Residence & & $14(33.3 \%)$ & \\
Urban & $38(43.7 \%)$ & $28(66.7 \%)$ & 0.329 \\
Rural & $49(56.3 \%)$ & & \\
\hline Occupation: & $9(10.3)$ & $7(16.7 \%)$ & \\
Retired & $28(32.2)$ & $8(19 \%)$ & \\
Housewife & $17(19.5)$ & $7(16.7 \%)$ & \\
workers & $33(37.9)$ & $20(47.6 \%)$ & \\
Employee & & & \\
\hline
\end{tabular}

Significant, DM: diabetes mellitus, IBS: inflammatory bowel syndrome, NA: not applicable.

Table 2: Positive B. hominis cases in IBS diabetic patients \& non-diabetic ones as to clinical pictures.

\begin{tabular}{|l|l|l|l|}
\hline Characteristics & IBS with DM positive culture N=87 & Non-DM negative culture N=42 & $P$-value \\
\hline Diarrhea & $67(77 \%)$ & $28(66.7 \%)$ & \\
Constipation & $20(23 \%)$ & $5(11.9 \%)$ & $<0.001^{*}$ \\
Alternating & $0(0 \%)$ & $9(21.4 \%)$ & \\
\hline Abdominal pain & $66(75.9 \%)$ & $30(71.4 \%)$ & 0.589 \\
\hline Anorexia & $44(50.6 \%)$ & $19(45.2 \%)$ & 0.570 \\
\hline Nausea & $44(50.6 \%)$ & $24(57.1 \%)$ & 0.484 \\
\hline Vomiting & $40(46 \%)$ & $20(47.6 \%)$ & 0.861 \\
\hline Flatulence & $51(58.6 \%)$ & $17(40.5 \%)$ & 0.053 \\
\hline DM treatment: Insulin & $26(29.9 \%)$ & & \\
\multicolumn{1}{|l}{ Oral } & $61(70.1 \%)$ & NA & --- \\
\hline
\end{tabular}

Table 3: Accuracy of direct wet mount smear and Lugol's Iodine staining compared to culture.

\begin{tabular}{|l|c|c|}
\hline Items & Direct wet mount & Lugol's iodine staining \\
\hline P-value & $0.003^{*}$ & $<0.001 * *$ \\
\hline Sensitivity & $38 \%(29.6-46.9)$ & $65.89 \%(57.0-74.0)$ \\
\hline Specificity & $87.32 \%(77.3-94)$ & $92.96 \%(84.3-97.7)$ \\
\hline Positive predictive value (PPV) & $84.5 \%(74.0-91.2)$ & $94.4 \%(87.9-97.6)$ \\
\hline Negative predictive value (NPV) & $43.7 \%(39.7-47.7)$ & $60 \%(53.9-65.8)$ \\
\hline Kappa & 0.207 & 0.524 \\
\hline Overall agreement & $55.5 \%$ & $75.5 \%$ \\
\hline
\end{tabular}


Table 4: Direct wet mount smear and Lugol's Iodine staining in diagnosing B. hominis as compared to culture.

\begin{tabular}{|c|c|c|c|c|c|c|c|c|}
\hline \multirow{2}{*}{\multicolumn{2}{|c|}{ Variants }} & \multicolumn{2}{|c|}{ IBS with DM } & \multicolumn{2}{|c|}{ IBS without DM } & \multicolumn{2}{|c|}{ Total } & \multirow[t]{2}{*}{$\mathrm{P}$ value } \\
\hline & & Count & $\%$ & Count & $\%$ & Count & $\%$ & \\
\hline \multirow{2}{*}{$\begin{array}{l}\text { Direct wet } \\
\text { mount }\end{array}$} & Yes & 37 & $37 \%$ & 21 & $21 \%$ & 58 & $29 \%$ & \multirow{3}{*}{$=0.013$} \\
\hline & No & 63 & $63 \%$ & 79 & $79 \%$ & 142 & $71 \%$ & \\
\hline \multicolumn{2}{|l|}{ Total } & 100 & $100 \%$ & 100 & $100 \%$ & 200 & $100 \%$ & \\
\hline \multirow{2}{*}{$\begin{array}{l}\text { Lugol's iodine } \\
\text { Staining }\end{array}$} & Yes & 65 & $65 \%$ & 25 & $25 \%$ & 90 & $45 \%$ & \multirow[t]{3}{*}{$<0.001$} \\
\hline & No & 35 & $35 \%$ & 75 & $75 \%$ & 110 & $55 \%$ & \\
\hline \multicolumn{2}{|l|}{ Total } & 100 & $100 \%$ & 100 & $100 \%$ & 200 & $100 \%$ & \\
\hline
\end{tabular}

Table 5: Multivariable binary logistic regression analysis of risk factors for B. hominis infection:

\begin{tabular}{|l|c|c|c|c|}
\hline Risk factors & \multirow{2}{*}{ P-value } & \multirow{2}{*}{ OR } & \multicolumn{2}{|c|}{ 95\% C.I. } \\
\cline { 4 - 5 } & & & Lower & Upper \\
\hline Groups (DM) & $<0.001 *$ & 9.393 & 4.570 & 19.309 \\
\hline Age (years) & 0.293 & 1.015 & 0.987 & 1.043 \\
\hline Sex (females) & 0.307 & 0.677 & 0.320 & 1.431 \\
\hline Occupation (working) & 0.794 & 0.895 & 0.390 & 2.054 \\
\hline Residence (rural) & 0.238 & 0.649 & 0.316 & 1.330 \\
\hline
\end{tabular}

\section{Discussion}

In the present study, $69 \%$ were females, in the IBS with DM patients, but without significant difference between blastocystosis and sexes. Alver and Töre (2006) found that blastocystosis infected patients were $67.9 \%$ males and 32.1\% females. Li et al. (2007) did not find significance among patients' sex. Dagci et al. (2014) reported that infection in females and males was more or less in equal ratio. Yunus et al. (2015) found that blastocystosis was $0.53 \%$ in males \& $0.56 \%$ in females and added that sex was not a risk factor, which negated a true relation between blastocystosis and sexes.

In the present study, infection was mostly in ages more than 50years in DM patients and controls. Cirioni et al. (1997) reported that ages and blastocystosis infection. Qadri et al. (1989) found that the infection was $71.8 \%$ among $13-50$ years and $19.3 \%$ in over 50. Blastocystis positive patients were predominantly between 20-29 years old (Dagci et al, 2014). But, Yunus et al. (2015) reported that the infection rate was high in 7-13 years aged children $(34.9 \%)$ and in 14-24 years aged teens $(24 \%)$. The discrepancy in age groups might be related to human behavior and epidemiological factors (Sheehan et al, 1986).

The present study showed that both DM patients and controls suffered from altered bowel habits with the predominance of diar- rhea. This was followed with bloating and flatulence with significant difference. Cirioni et al. (1997) reported that immunocompromised patients with various disorders, such as acquired immunodeficiency syndrome, leukemia, and bad controlled diabetes were prone to develop $B$. hominis infections. Yakoob et al. (2004) reported that B. hominis infection caused the irritable bowel syndrome (IBS). Blastocystis colonization was significantly associated with a higher diversity of the gut bacterial communities in healthy children (Kodio et al, 2019).

In the present study, IBS diabetic patients' samples were diagnosed by direct wet mount smear (37\%), Lugol's iodine staining (65\%) and Modified Jones' culture (87\%). But, parasitic diagnosis in IBS control patients was $21 \%, 25 \%$, \& $42 \%$ samples respectively. Kucsera et al. (2014) reported 20.5\% Blastocystis positive cases by microscopy compared to $38.8 \%$ by culture. Suli et al. (2018) found that $21 / 48(43.75 \%)$ samples were positive by direct smear examination, and 38/ 48 (79.17\%) were positive by Jones' culture. Nghaimesh et al. (2018) reported that by wet mount smear showed that $51.95 \%$ of IBS patients were infected with $B$. hominis. El Sayad et al. (2019) found that $B$. hominis was positive in $52 \%$ by light microscopy and $65 \%$ by culture media.

In the present work, by using culture as reference method, sensitivity and specificity 
of wet mount smear were $38 \%$ \& $87.32 \%$ respectively, and by iodine staining were $65.89 \%$ \& $92.96 \%$ respectively. Kukosche et al. (1990) did not find any difference between culture and microscopy diagnosis. Baiomy et al. (2010) found that majority $B$. hominis patients with had chronic diseases such as DM. Suli et al. (2018) found that the sensitivity of direct wet mount was $46.15 \%$, while the sensitivity of culture was $84.62 \%$ when compared with PCR. El Sayad et al. (2019) reported that the sensitivity of culture was better than both microscopy and iodine staining and that the culture proved to be a reliable method, but with time-consuming Laodim et al. (2012) recorded that Blastocystis was common in $25.8 \%$ of patients with underlying DM disease. Also, Mohtashamipour et al. (2015) reported that the risk of intestinal parasites was 3.6 times greater in patients with DM than in healthy people, especially with $B$. hominis, which flourished in the damaged intestinal mucosal integrity in DM causing, sever GIT complaints. Moreover, Drawany et al. (2019) reported that blastocystosis was the second major intestinal parasitosis among DM patients.

\section{Conclusion}

Diabetes mellitus must be considered as a risk factor for intestinal opportunistic infections especially Blastocystis species. Besides, blastocystosis proved to be one of the common parasites in the IBS patients. Thus, stool screening is a must for both IBS and diabetic patients to identify blastocystosis.

\section{References}

Alfellani, MA, Stensvold, CR, Vidal-Lapiedra, A, Onuoha, ES, Fagbenro, AF, et al, 2013: Variable geographic distribution of Blastocystis subtypes and its potential implications. Acta Trop. 126, 1:11-8.

Alver, O, Töre, $O$ 2006: The prevalence and distribution of intestinal parasites detected by the Uludag University Medical School. Turk. Parazitol. Derg. 30, 4:296-301.

Abdel Fadil, EE, Ismail, MAM, Morsy, TA, 2018: Eosinophilia with special reference to helminthiasis. J. Egypt. Soc. Parasitol. 48, 2:465-74 Aulagnon, F, Scemla, A, de Wolf, S, Legend- re, C, Zuber, J, 2014: Diarrhea after kidney transplantation: A new look at a frequent symptom. Transplantation 98, 8:806-16.

Baiomy, AM, Mohamed, KA, Ghannam, MA, Shahat, SA, Al-Saadawy, AS, 2010: Opportunistic parasitic infections among immunocompromised Egyptian patients. J. Egypt. Soc. Parasitol. 40, 3:797-808.

Berbudi, A, Rahmadika, N, Tjahjadi, AI, Ruslami, R, 2020: Type 2 Diabetes and its Impact on the Immune System. Curr. Diabet. Rev. 16, 5: 442-9.

Bogoch, II, Raso, G, Goran, EK, Marti, HP, Utzinger, J, 2006: Differences in microscopic diagnosis of helminths and intestinal protozoa among diagnostic centres. Eur. J. Clin. Microbiol. Infect. Dis. 25:344-7.

Boorom, KF, Smith, H, Nimri, L, Viscogliosi, E, Spanakos, G, et al, 2008: Oh my aching gut: Irritable bowel syndrome, Blastocystis, and asymptomatic infection. Parasit. Vect. 1:40-6.

Cirioni, O, Giacometti, A, Drenaggi, D, Ancarani, F, Scalise, G, 1997: Prevalence and clinical relevance of Blastocystis hominis in diverse patient cohorts. Eur. J. Epidemiol. 15:3890-93.

Coyle, CM, Varughese, J, Weiss, LM, Tanowitz, HB, 2012: Blastocystis: To treat or not to treat. Clin. Infect. Dis. 54:105-10.

Dagci, H, Kurt, O, Demirel, M, Mandiracioglu, A, Aydemir, S, et al, 2014: Epidemiological and diagnostic features of Blastocystis infection in symptomatic patients in Izmir Province, Turkey. Iran. J. Parasitol. 9:519-29.

Drawany, ZEE, Saleh, SHA, Etewa, SES, et al, 2019: Prevalence of intestinal parasites among type 1 diabetic patients in pediatrics Zagazig university hospital. Endocrinol. Metab. Int. J. 7, 6:171-9.

El Sayad, MH, Tolba, MM, Argiah, HA, Gaballah, A, et al, 2019: Electron microscopy of $B l$ astocystis hominis and other diagnostic approaches, J. Egypt. Soc. Parasitol. 49, 2:373-80.

El-Tawdy, AHF, Ibrahim, EA, Abdallah, E S, Al Sakhawy EMA, Morsy, TA, 2016: Screening for the diabetes mellitus: General information for patients to avoid foot amputation. EMMJ 71, 1:61 -74

Eroglu, F, Genc, A, Elgun, G, Koltas, IS, 2009: Identification of Blastocystis hominis isolates from asymptomatic and symptomatic patients by PCR. Parasitol. Res. 105:1589-92.

Hassan, MA, Rizk, EM, Wassef, RM, 2016: Modified culture methodology for specific dete- 
ction of blastocystis hominis in stool samples. J. Egypt. Soc. Parasitol. 46, 3:541-8.

Hussain, R, Jaferi, W, Zuberi, S, et al, 1997: Significantly increased IgG2 subclass antibody levels to Blastocystis hominis to patients with irritable bowel syndrome. Am. J. Trop. Med. Hyg. 56:301-6.

Knapp, S, 2013: Diabetes and infection: Is there a link? A mini-review. Gerontology 59, 2:99104.

Kodio, A, Coulibaly, D, Koné, AK, Konaté, S, Doumbo, S, 2019: Blastocystis colonization is associated with increased diversity and altered gut bacterial communities in healthy Malian Children. Microorganisms 7, 12:649.

Kucsera, I, Molnar, M, Glyasz, E, Danka, J, Orosz, E, 2014: ELISA test for detection of Blaststocystis spp. in human faces: Comparison of three methods. Budapest, Hungary: National center for epidemiology

Kukoschke, KG, Necker, A, Müller, HE, 1990: Detection of Blastocystis hominis by direct microscopy and culture. Eur. J. Clin. Microbiol. Infect. Dis. 9, 4:305-7.

Laodim, P, Intapan, PM, Sawanyawisuth, K, Laummaunwai, P, Maleewong, W, 2012: A hospital based study of epidemiological and clinical data on Blastocystis hominis infection. Foodborne Patho. Dis. 9, 12:1077-82.

Lepczyńska, M,Dzika, E, Kubiak, K, Korycińska, J, 2016: The role of Blastocystis sp. as an etiology of irritable bowel syndrome. Polish Ann. Med. 23, 1:57-60.

Li, M, Cha, DJ, Lai, Y, Villaruz, AE, Sturdevant, DE, et al, 2007: The antimicrobial peptide, sensing system aps of Staphylococcus aureus. Mol. Microbiol. 66, 5:1136-47.

Meloni, D, Sanciu, G, Poirier, P, El Alaoui, H, Chabe, M, et al, 2011: Molecular subtyping of Blastocystis sp. isolates from symptomatic patients in Italy. Parasitol. Res. 109, 3:613-9.

Mohtashamipour, M, Ghaffari, HS, Pestehchian, N, Yousefi, H, Fallah, E, et al, 2015: Intestinal parasitic infections in patients with Diabetes Mellitus: A case-control study. J. Anal. Res. Clin. Med. 3, 3:157-63.

Nascimento, SA, MoitinhoMda, L. 2005: Blastocystis hominis and other intestinal parasites in a community of Pitanga City, Paraná State, Brazil. Rev. Inst. Med. Trop. Sao Paulo 47:213-7.

Nghaimesh, SK, Mohammad, NSH, Kader, M
A, 2018: Gene sequencing of Blastocystis hominis and its association with $H$. pylori in the development of irritable bowel syndrome. Kirkuk Univ. J. Sci. Stud. 13, 1:289-303.

Qadri, SM, Al-Okaili, GA, Al-Dayel, F, 1989: Clinical significance of Blastocystis hominis. J. Clin. Microbiol. 27, 11:2407-9.

Roden, M, 2016: Diabetes mellitus: Definition, classification and diagnosis. Wien. Klin. Wochenschr. 128, 2:S37-40

Scanlan, PD, 2012: Blastocystis: Past pitfalls and future perspectives. Trend. Parasitol. 28: 327-34.

Sheehan, DJ, Raucher, BG, McKitrick, JC, 1986: Association of Blastocystis hominis with signs and symptoms of human disease. J. Clin. Microbiol. 5:48-50.

Stark, D, Barratt, JLN, van Hal, S, Marriott, D, Harkness, J, et al, 2009: Clinical significance of enteric protozoa in the immunosuppressed human population. Clin. Microbiol. Rev. 22, 4: 634-50.

Suli, T, Kozoderović, G, Potkonjak, A, Simin, S, Simin, V, et al, 2018: Comparison of conventional and molecular diagnostic techniques for detection of Blastocystis sp. in pig feces. Iran J. Parasitol. 13, 4:594-601.

Suresh, K, Smith, H, 2004: Comparison of methods for detecting Blastocystis hominis. Eur. J. Clin. Microbiol. Infect. Dis. 23:509-11.

Tanaka, Y, 2008: Immunosuppressive mechanisms in diabetes mellitus. Nihon Rinsh. 66, 12: 2233-7.

Yaicharoen, R, Ngrenngarmlert, W, Wongjindanon, N, Sripochang, S, Kiatfuengfoo, R, 2006: Infection of Blastocystis hominis in primary schoolchildren from Nakhon-Pathom Province, Thailand. Trop. Biomed. 23:117-22.

Yakoob, J, Jafri, W, Jafri, N, Islam, M, AsimBeg, M, 2004: In vitro susceptibility of Blastocystis hominis isolated from patients with irritable bowel syndrome. Brit. J. Biomed. Sci. 61, 2:75-7.

Yunus, E, Yilmaz, H, Cengiz, ZT, Ekici, A, 2015: Clinical significance and prevalence of $B l$ astocystis hominis in Van, Turkey. Saudi Med. J. 36, 9:1118.

Zheng, Y, Ley, SH, Hu, FB, 2018: Global aetiology and epidemiology of type 2 diabetes mellitus and its complications. Nat. Rev. Endocrinol. 14, 2:88-98. 